\title{
STUDY OF FIBER OPTIC SENSOR USING CONCRETE BEAMS
}

\author{
Sabih Ahmad ${ }^{1}$, Muddassir Umer Rizvi ${ }^{2}$, Syed Mohd. Ashraf Husain ${ }^{3}$, Abdullah Anwar \\ ${ }^{1}$ Associate Prof., Civil Engineering Department, Integral University, Uttar Pradesh (Lucknow), India \\ ${ }^{2}$ Assistant Prof., Civil Engineering Department, Integral University, Uttar Pradesh (Lucknow), India \\ ${ }^{3}$ Assistant Prof., Civil Engineering Department, Integral University, Uttar Pradesh (Lucknow), India \\ ${ }^{4}$ Assistant Prof., Civil Engineering Department, Integral University, Uttar Pradesh (Lucknow), India
}

\begin{abstract}
Monitoring of important structures throughout its working life is normally needed to ensure its performance under expected applied loads. This usually involves investigation of cracking and damage due to applied loads, corrosion of steel, failure of bonds, excessive strain in concrete and reinforcing bars, critical deflection etc. The conventional techniques such as strain gauges, vibrating wires strain translucers, etc. have their own limitations. These sensors may not be functional and effective sensor throughout the life of structures. This being the position, the need of development of effective senor was being felt quite long. In recent years fiber optic based sensors have attracted considerable interest as non destructive structural health monitoring technique. In this research embedded fiber optic sensors are developed to monitor reinforced concrete beams. Embedded fiber optic sensor responded very well under the applied loads and any change in the intensity of light can be considered as a warning even before the cracks are visible on the outer surface. This characteristic of embedded fiber optic sensors can be used as a crack detection tools.
\end{abstract}

Keywords: Crack detection, fiber optic sensors, monitoring, smart structures.

\section{INTRODUCTION}

In recent years going interest has been emerged in the area of fiber optic sensor for smart civil engineering structures. A smart structure is capable of accessing damage and warning of impending weakness in structural integrity. Fiber optic sensors offers many advantages over conventional electronic system when applied to civil structures as the overall size of most civil structures poses many problems which may possibly be overcome by using fiber optic sensors. Fiber optic sensors are light weight, non hindering, can be configured to arbitrary shapes, low power utilization, flexibility, immune to electric and electromagnetic interference. The most important feature of fiber optic sensors is that it serves both as sensing element and signal transmission medium, allowing the electronic instrumentation to be located remotely from the measurement site. Thus the application of these sensors may lead to designing an implementation of safer building and structures.

\subsection{Basis of Light Transmission in Optical Fiber}

Snell's Law and the concept of total internal reflection can explain the transmission of light through optical fiber. Snell's Law relates index of refraction and incoming and outgoing angles for light passing from one material to another by the equation :

$$
\mathbf{N}_{1} \operatorname{Sin} \theta_{1}=\mathbf{N}_{2} \operatorname{Sin} \theta_{2}
$$

When a light travels from a fiber core that has higher refractive index (1.46) into the cladding with a lower refractive index (1.40), the light wave is totally reflected back into the core as shown in fig. 1

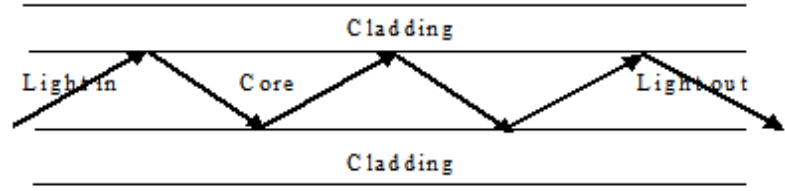

\subsection{Application of Fiber Optic Sensor for Concrete}

The use of fiber optic technology in the telecommunication industry has started as early as in the mid 1960's. Since then the success of fiber optic technology in the field of communication engineering as well as various other fields has recently lead to research and development activities of this technology in Civil Engineering also.

Mathews and Sirkis [1] used embedded optical fiber sensor as a single phase component to observe strain concentration in homogenous and isotropic host. Narendran, Shukla and Letcher [2] attached optical fibers sensors to a cantilever beam for strain measurement. J.K. Chhabra et al. [3] embedded optical fiber sensors in concrete beam to monitor the overall health of structures. Rossi and Lee Maon [4] embedded optical fibers sensors in reinforced concrete beams to detect cracks under the action of applied loads. Wolff and Meisseler [5] developed fiber optic sensor for monitoring of pre-stressing force and crack formation in Schiessbergstrasse Bridge in Germany. Xianglim Gu, et al. [6] developed embedded optical fiber sensors for crack detection in reinforce concrete structure. An optical time domain reflectometer (OTDR) was used for the operation of 
sensors signal. Pandey [7] used fiber optic sensors for monitoring of structural defects.

\section{EXPERIMENTAL DETAILS}

A set of three reinforced concrete beams of section $10 \mathrm{~cm} \mathrm{x}$ $10 \mathrm{~cm} \times 75 \mathrm{~cm}$ and reinforced with $2 \# 8 \mathrm{~mm} \phi$ bars at bottom and $2 \# 8 \mathrm{~mm} \phi$ at top were casted. Prior to pouring in concrete into form, fiber optic sensor was pasted at mid span on one of the bottom reinforcing bars. Concrete control cubes were also casted to measure the actual concrete strength. Beams and cubes were casted in M 20 mix and the beam was reinforced with $\mathrm{Fe} 415$ grade steel. The water cement ratio was adopted as 0.60 .

\subsection{Material Properties}

Following are the properties of material used in construction of test beams:

(a) Cement - Portland Pozzolana cement (43Grade) has been used in the mix. The physical properties were determined in the laboratory as per IS: 269-1967 and are given below:

(i) Consistency $=34 \%$

(ii) Initial setting time (minutes) $=40$

(iii) Final setting time (minutes) $=600$

(b) Fine Aggregate - Locally available coarse sand has been used as fine aggregate. The fineness modulus was found as 2.70 .

(c) Coarse Aggregate - Locally available crushed stone aggregate, $20 \mathrm{~mm}$ maximum size has been used.

(d) Water - For both mixing and curing of the specimen potable water has been used.

\subsection{Circuit Used}

Circuit used in this study basically comprises of transmitter unit and receiving unit. The transmitter unit consists of a light emitting diode while the receiving unit consists of a photo-diode. The various disturbances, which may be present in the supply, are suppressed in this circuit. The final output voltage is monitored on an oscilloscope.

\subsection{Optical Fiber Used}

In the present experimental study multimode step index plastic fiber of $1 \mathrm{~mm}$ diameter has been used. Although glass fibers are more precise than plastic fibers for receiving and transmitting light signal, but these are highly brittle and cannot be embedded inside the concrete.

\subsection{Sensing Technique Employed}

The sensing technique in this study is simply to cleave the end of optical fiber and placing them into a capillary tube. A very small air-gap is provided between the two cleaved ends of the optical fiber in the capillary tube (fig.1). Due to extended disturbance the air-gap in the tube is either shortened or widened resulting in corresponding gain or loss of light intensity passing through the optical fiber. The fiber optic sensing devices comprises of a light source for injecting a signal into the sensor fiber, a light detector for receiving the signal after the light has been modulated by the optical fiber sensor and an electronic system for processing the detected light into useful electrical quantity.

\subsection{Load Arrangements and Instrumentation}

After 28 days of curing, the test beam was put in position to test under incrementally applied flexural load. Before applying the load, a dial gauge was fixed to measure the deflection at mid-span (fig. 2). The fiber ends coming out of the beam are connected to the circuit and connections are checked properly. Load is applied at mid-span through UTM. Observations were recorded for deflection in the dial gauge and intensity losses (attenuation) in the oscilloscope.

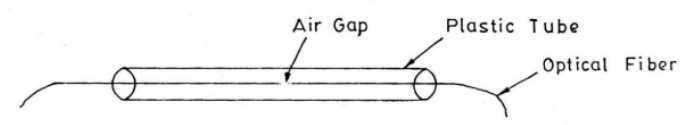

Fiber Optic Sensor

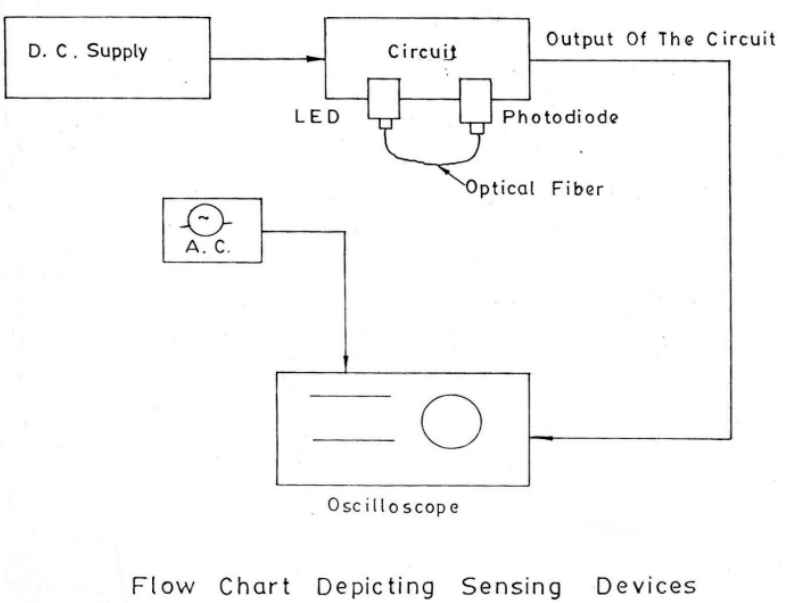

Fig. 1

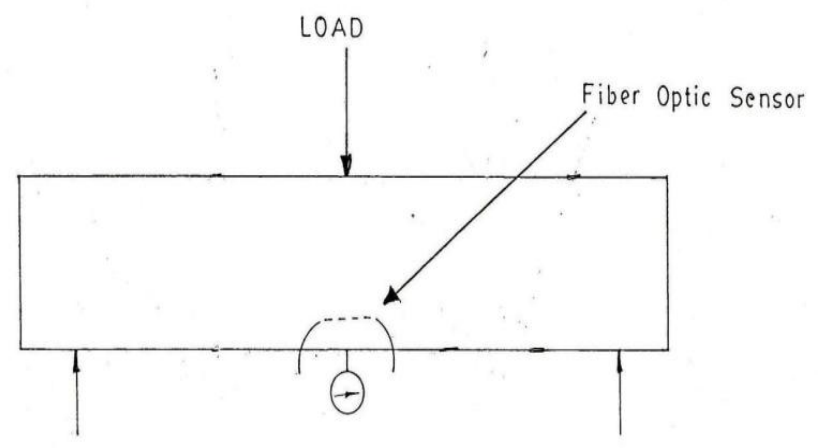

Fig. 2 


\section{RESULTS AND DISCUSSIONS}

Load verses Deflection curves for test Beam 1, Beam 2 and Beam 3 respectively (Fig. 3). Load verses Attenuation (change in intensity of light) curves for test Beam 1, Beam 2 and Beam 3 respectively (Fig. 4). Deflection verses Attenuation curves for test Beam 1, Beam 2 and Beam 3 respectively (Fig. 5). The attenuations were measured on embedded optical fiber sensors provided in the test beams at the level of steel at mid-span while the deflection was measured by dial gauge at mid-span.

As seen in figure 3, Load vs. Deflection relation is almost linear up to a load of $25 \mathrm{kN}$ and the rate of change of deflection is small whereas beyond this value of the load, the deflection increases rapidly. The crack in beam appears first at $30 \mathrm{kN}$. It means that the beam shows a ductile behavior in the post cracking range. The same pattern is observed in the Load vs. Attenuation curve (Fig. 4). Initially the variation is almost linear up to a load of $25 \mathrm{kN}$ after which intensity losses are higher for the same increment of load. During the experiment it is found that at a load of about $30 \mathrm{kN}$ cracks appear on the beam surface but before that there is a considerable loss in the intensity of light, which may be due to crack formation (invisible) in the beam. This characteristic of embedded fiber sensor can be used as a crack detection tool.

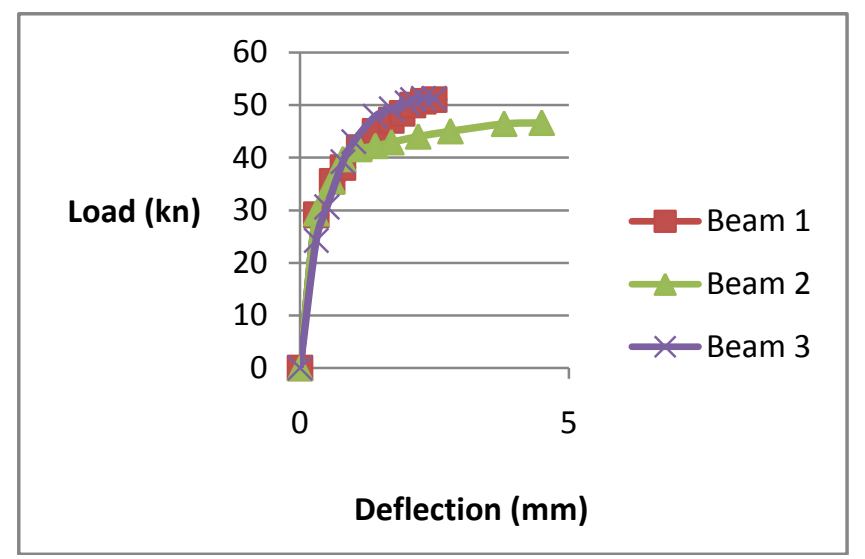

Fig.3 Load vs. Deflection

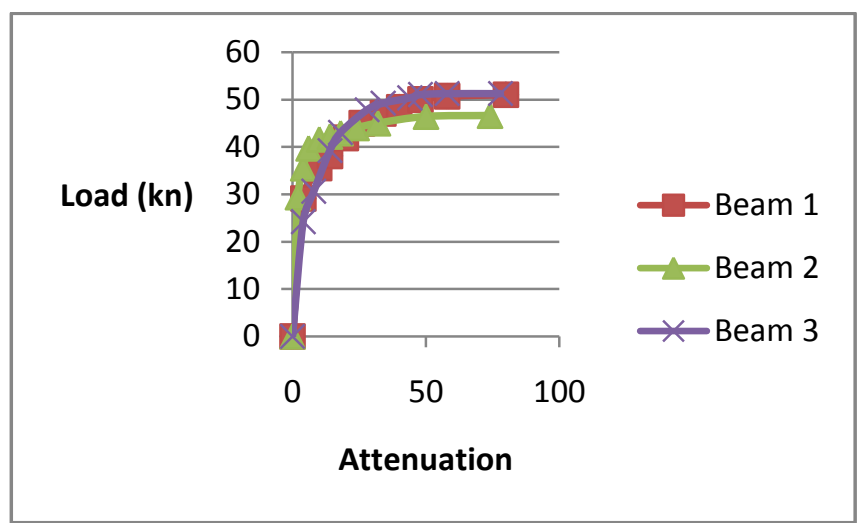

Fig. 4 Load vs. Attenuation

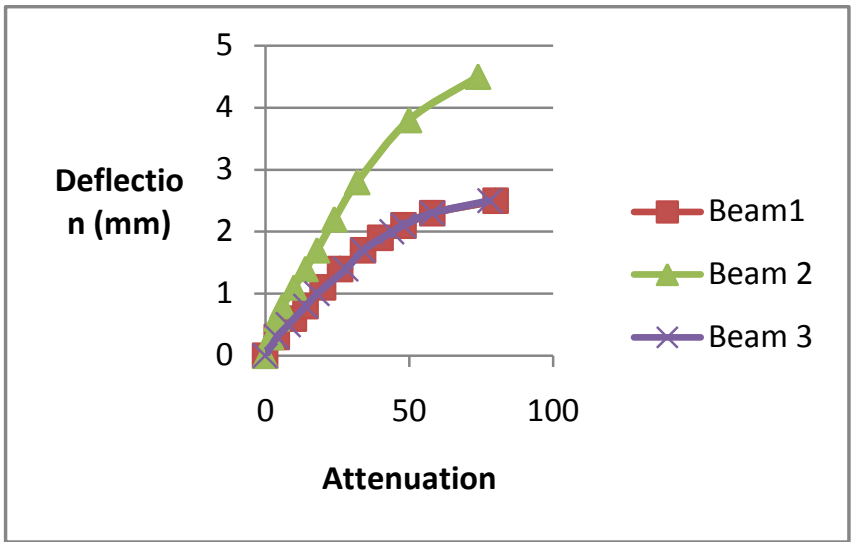

Fig. 5 Deflection vs. Attenuation

\section{CONCLUSIONS}

Embedded fiber optic sensors responded very well under the applied load. Thus any change in the intensity of light can be considered as a warning even before the cracks are visible on the outer surface. This characteristic of embedded optical fiber sensors can be used as a crack detection tool. There is a need of further précising the instruments so that the pre-cracking behavior can be more precisely examined. This is an inter-disciplinary field and requires expertise in concrete engineering as well as in physics and optoelectronics. Researchers rely on materials and instrumentation developed for the communication industry, mainly due to the fact that there are no dedicated tools for sensor research in the construction industry.

\section{REFERENCES}

[1]. Mathews, C.T. and Sirkis, J.S., “ The interaction mechanics of inter ferrometric optical fiber sensors embedded in monolithic structures," Fiber optic smart structures and Skins III, Vol. 1370, Society of photo optical instrumentation, San Jose, CA, 1990 pp. 142-153.

[2]. Narendran, N., Shukla, A., and Letcher, S., "Optical Fiber Interferrometric strain sensor using a single fiber," Concrete. Nov/Dec (1992). Pp. 33-36

[3]. Chhabra, J.K., Shah, M.L., Kumar, A., and Aggarwal, A.K., "Embedded fiber optic sensors for reinforced concrete structures". Communication in instrumentation, Vol. 6, No. 1, April-June 1998, Pp. 40-46

[4]. Rossi, P. and Lee Maon, F., "New method of detecting cracks in concrete using fiber optics", RILEM Mater. Struc. 22(1989), Pp.437-442.

[5]. Wolff, R., and Meisseler, "Application with optical fiber sensor systems for monitoring pre-stressed concrete structures," Structures Congress Abstracts, ASCE, New York, 1990, Pp.94-95.

[6]. Xianglin G. W., Zhongyuchen and Ansari, F., "Embedded Fiber optic crack sensors for reinforced concrete structures, ACI Structural Journal, May-June 2000, Pp.468476.

[7]. Pandey, N.K., “ Fiber optic pressure sensor for monitoring of structural defects." Optica applicata, Vol. XXXVII, No. 1-2, 2007 


\section{BIOGRAPHIES}

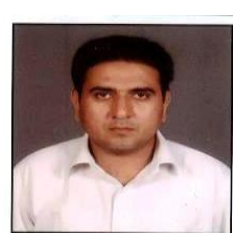

Sabih Ahmad, Associate Prof., Department of Civil Engineering, Integral University, Lucknow

Specialization: Structures

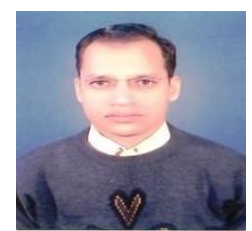

Muddassir Umer Rizvi, Assistant Prof., Department of Civil Engineering, Integral University, Lucknow

Specialization: Structures

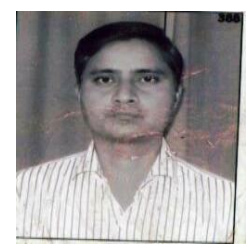

Syed Mohd. Ashraf Husain, Assistant Prof., Department of Civil Engineering, Integral University, Lucknow

Specialization: Structures

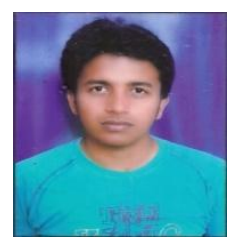

Abdullah Anwar, Assistant Prof., Department of Civil Engineering, Integral University, Lucknow

Specialization: Structures 